\title{
Vitamin D and mucosal immune function
}

\author{
Jun Sun \\ Department of Medicine, University of Rochester, Rochester, New York, USA
}

\begin{abstract}
Purpose of review-Significant advances have been made in the characterization of Vitamin D and the Vitamin D receptor (VDR) in immune function. The studies of signaling pathways involved in the response to infection and inflammation have led to a more detailed understanding of the cellular response to Vitamin D through VDR. This review summarizes recent progress in understanding how Vitamin D contributes to mucosal immune function, particularly in relation to the molecular mechanisms by which Vitamin D and VDR influence mucosal immunity, bacterial infection, and inflammation.
\end{abstract}

Recent findings-Recently, it was shown that Vitamin D modulates the $\mathrm{T}$ cell antigen receptor, further demonstrating that Vitamin D has a nonclassical role in immunoregulation. The antiinflammation and anti-infection functions for Vitamin $\mathrm{D}$ are newly identified and highly significant activities. Vitamin D/VDR have multiple critical functions in regulating the response to intestinal homeostasis, tight junctions, pathogen invasion, commensal bacterial colonization, antimicrobe peptide secretion, and mucosal defense. Interestingly, microorganisms modulate the VDR signaling pathway.

Summary-Vitamin D is known as a key player in calcium homeostasis and electrolyte and blood pressure regulation. Recently, important progress has been made in understanding how the noncanonical activities of Vitamin D influence the pathogenesis and prevention of human disease. Vitamin $\mathrm{D}$ and VDR are directly involved in T cell antigen receptor signaling. The involvement of Vitamin D/VDR in anti-inflammation and anti-infection represents a newly identified and highly significant activity for VDR. Studies have indicated that the dysregulation of VDR may lead to exaggerated inflammatory responses, raising the possibility that defects in Vitamin D and VDR signaling transduction may be linked to bacterial infection and chronic inflammation. Further characterization of Vitamin D/VDR will help elucidate the pathogenesis of various human diseases and in the design of new approaches for prevention and treatment.

\section{Keywords}

bacteria; infection; inflammation; Vitamin D; Vitamin D receptor

\section{Introduction}

Vitamin D is known to modulate calcium homeostasis and has a role in the regulation of electrolytes and blood pressure [1]. There is now an increasing amount of evidence to show that $1,25(\mathrm{OH})_{2} \mathrm{D}_{3}$, the most active metabolite of Vitamin $\mathrm{D}$, regulates the immune response and possesses anti-inflammatory activity. This article reviews recent advances towards 
elucidating the mechanism by which Vitamin $\mathrm{D}$ affects mucosal immunity and discusses the role of Vitamin D in immunologic homeostasis, especially in the gastrointestinal tract.

\section{Effects of $1,25(\mathrm{OH})_{2} \mathrm{D}_{3}$ on the immune system}

Approximately $3 \%$ of the mouse and human genomes are regulated directly or indirectly by the Vitamin D endocrine system $[2 \bullet, 3,4 \bullet]$. Vitamin D deficiency is a critical factor in the pathology of at least 17 varieties of cancer as well as autoimmune diseases, diabetes, osteoarthritis, periodontal disease, and more. These data suggest that Vitamin D functions in a wide variety of diseases (http://www.vitamindcouncil.org). Recently, there have been significant improvements in our understanding of how the unconventional functions of Vitamin D influence the pathogenesis and prevention of human diseases [5].

The mucosal immune system has three main functions [6]: protecting the mucus membrane against infection, preventing the uptake of antigens, microorganisms, and other foreign materials, and moderating the organism's immune response to that material.

The tissue-specific synthesis of active $1,25(\mathrm{OH})_{2} \mathrm{D}_{3}$ from its precursor $25 \mathrm{OHD}$ has been shown to be important for both the innate and the adaptive immune systems $[5,7]$.

A recently published study has shown that Vitamin D directly modulates the $\mathrm{T}$ cell antigen receptor (TCR) [8••]. In naive T cells, low expression of phospholipase C $\gamma 1$ (PLC) is correlated with low TCR responsiveness. The induction of PLC- $\gamma 1$ is shown to be dependent on Vitamin D and Vitamin D receptor (VDR). Naive T cells do not express VDR, but initial TCR signaling via the alternative mitogen-activated protein kinase $\mathrm{p} 38$ leads to successive induction of VDR and PLC- $\gamma 1$, which are required for subsequent classical TCR signaling and T cell activation $[8 \cdot \bullet]$.

Overall, the effects of $1,25(\mathrm{OH})_{2} \mathrm{D}_{3}$ on the immune system include modulating the TCR, decreasing Th1/Th17 CD4+ T cells and cytokines, increasing regulatory T cells, downregulating $\mathrm{T}$ cell-driven IgG production, and inhibiting dendritic cell differentiation. In addition, $1,25(\mathrm{OH})_{2} \mathrm{D}_{3}$ helps maintain self-tolerance by dampening overly zealous adaptive immune responses while enhancing protective innate immune responses [9•].

\section{Vitamin D receptor, intestinal Vitamin D receptor, and immunity}

VDR is a nuclear receptor that mediates most known functions of $1,25(\mathrm{OH})_{2} \mathrm{D}_{3}$. Active VDR affects transcription of at least 913 genes and impacts processes ranging from calcium metabolism to the expression of key antimicrobial peptides [10•]. Thus, the traditional model that was used to guide the early vitamin studies is now giving way to a more complex mechanism of action.

Using VDR null mice, a great deal has been learned about the physiological functions of VDR in human diseases [3]. The intestine is the key target of the VDR because of the high calcium intake. VDR is essential for proper control of bone formation, renal control of serum 1,25 $(\mathrm{OH})_{2} \mathrm{D}_{3}$, and urinary calcium excretion $[3,11]$.

Many studies have implicated Vitamin D and VDR in inflammatory bowel disease (IBD) [12]. Low Vitamin D levels have been reported in patients with IBD. The VDR protein is significantly lower in IBD and colitis-associated colon cancer patients [13,14]. In experimental models, both local and endocrine synthesis of $1,25(\mathrm{OH})_{2} \mathrm{D}_{3}$ affect the development of murine colitis. VDR status affects the development of murine colitis and $\mathrm{T}$ cell homing in intestine [15]. It has also been shown that VDR stabilizes cell tight junction structures in the intestinal 
epithelial cells [16,17]; hence, proper functioning of VDR is needed to control intestinal homeostasis.

\section{The anti-inflammatory mechanisms of $1,25(\mathrm{OH})_{2} \mathrm{D}_{3}$ and Vitamin $\mathrm{D}$ receptor}

Consistent with its anti-inflammatory role, $1,25(\mathrm{OH})_{2} \mathrm{D}_{3}$ downregulates the expression of many proinflammatory cytokines, such as IL-1, IL-6, IL-8, and TNF- $\alpha$, in a variety of cell types $[9 \bullet, 12]$. Immune cells, including macrophages, dendritic cells, and activated T cells, express the intracellular VDR and are responsive to $1,25(\mathrm{OH})_{2} \mathrm{D}_{3}$.

A recent study showed that the stimulation of CD4(+) CD25(-) T cells in the presence of 1,25 $(\mathrm{OH})_{2} \mathrm{D}_{3}$ inhibits the production of proinflammatory cytokines, including IFN- $\gamma, \mathrm{IL}-17$, and IL-21, but does not substantially affect $T$ cell division. In contrast to its inhibitory effects on inflammatory cytokines, $1,25(\mathrm{OH})_{2} \mathrm{D}_{3}$ stimulates the expression of CTLA-4 and FoxP3, the latter requiring the presence of IL-2. Thus, $1,25(\mathrm{OH})_{2} \mathrm{D}_{3}$ and IL-2 have direct synergistic effects on activated $\mathrm{T}$ cells, acting as potent anti-inflammatory agents and physiologic inducers of adaptive regulatory $\mathrm{T}$ cells $[18 \bullet]$.

The NF- $\kappa B$ pathway is negatively regulated by $1,25(\mathrm{OH})_{2} \mathrm{D}_{3}$ and VDR [19] because the VDRp65 interaction helps suppress p65 activity [20]. Moreover, the absence of VDR in cells leads

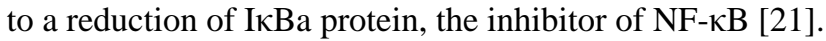

In addition, $1,25(\mathrm{OH})_{2} \mathrm{D}_{3}$ robustly stimulates the expression of the pattern recognition receptor NOD2/CARD15/IBD1 gene and protein in primary human monocytes and epithelial cells. Pretreatment of cells with $1,25(\mathrm{OH})_{2} \mathrm{D}_{3}$ synergistically decreased the NF- $\kappa \mathrm{B}$ activity, the expression of genes encoding DEFB2/HBD2, and the antimicrobial peptide cathelicidin in the presence of the agonist muramyl dipeptide [22•]. Importantly, this synergistic response has also been seen in macrophages from a donor with wild type NOD2, but was absent in macrophages from Crohn's disease patients with homozygous alleles for nonfunctional NOD2 variants. These studies provide molecular links between Vitamin D deficiency and the genetics of Crohn's disease [22•].

In summary, the regulation of T cells, B cells, macrophages, dendritic cells, and epithelial cells by $1,25(\mathrm{OH})_{2} \mathrm{D}_{3}$ and VDR provides a link between Vitamin D and many autoimmune diseases, including IBD, juvenile diabetes mellitus, multiple sclerosis, asthma, and rheumatoid arthritis [23].

\section{Battles against pathogens at mucosal surfaces through Vitamin D and Vitamin $D$ receptor}

Vitamin D deficiency has been correlated with increased rates of infection. Moreover, 1,25 $(\mathrm{OH})_{2} \mathrm{D}_{3}$ induces the expression of antimicrobial peptides, such as cathelicidin. Thus, recent studies have greatly renewed interest in the anti-infection activity of $1,25(\mathrm{OH})_{2} \mathrm{D}_{3}[24 \cdot]$.

A number of autoimmune diseases have been shown to be reversed by gradually restoring VDR function with the VDR agonist olmesartan and subinhibitory dosages of certain bacteriostatic antibiotics [25]. Diseases showing favorable responses to treatment so far include systemic lupus erythematosis, rheumatoid arthritis, scleroderma, sarcoidosis, Sjogren's syndrome, autoimmune thyroid disease, psoriasis, ankylosing spondylitis, Reiter's syndrome, type I and II diabetes mellitus, and uveitis [25].

Both autophagy and Vitamin D3-mediated innate immunity have been shown to confer protection against infection with intracellular Mycobacterium tuberculosis. Further studies have demonstrated that human cathelicidin serves as a mediator of Vitamin D3-induced 
autophagy $[26 \bullet, 27]$. Effective innate immunity against many microbial pathogens requires macrophage responses that upregulate phagocytosis and direct antimicrobial pathways. Recent data indicate that IL-15 induces the Vitamin D-dependent antimicrobial pathway and CD209 [28•].

Cells of the gastrointestinal tract, including epithelial cells and lamina propria macrophages, are constantly exposed to lumenal bacteria, which play key roles in normal intestinal development and innate immunity. The intestinal Paneth cells are known to secrete antimicrobial peptides, which are regulated by VDR signaling [26•]. Paneth cells seem to be key players, highlighting the paramount importance of the antimicrobial host defense in the pathogenesis of Crohn's disease [29,30]. Recent studies indicate that VDR-/- mice have increased bacterial loads in the intestine [31•]. Our studies demonstrate that VDR signaling responds to pathogenic Salmonella in the intestine in vivo [20]. At the intestinal mucosal surfaces, Shigella is also known to decrease the abundance of antimicrobial peptides, which are regulated by Vitamin D signaling [32].

The study of D'Aldebert et al. [33•] reported that biliary epithelial cells in the human liver have intense immunoreactivity for cathelicidin and for the VDR. Bile salts may contribute to biliary tract sterility by controlling epithelial cell innate immunity. Their data suggest that for inflammatory biliary diseases, which involve bacterial factors, a strategy that systematically combines therapeutic bile salt, ursodeoxycholic acid, and Vitamin D would increase therapeutic efficacy.

Vitamin D has also been shown to be involved in upper respiratory tract infections [34] and

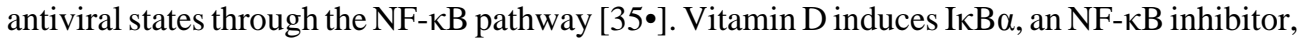
and decreases respiratory syncytial virus induction of NF-אB-driven genes, such as IFN- $\beta$ and CXCL10, in the airway epithelium. Moreover, Vitamin D decreases the inflammatory response to viral infections without jeopardizing viral clearance [35•].

The majority of studies that have been published on Vitamin D have been focused on immunoregulation with little emphasis on assessing the status and function of VDR in epithelial cells. The regulation of the antimicrobial peptide cathelicidin by VDR is through both the endocrine and the xenobiotic systems. Studies in humans and humanized mouse models will elucidate the importance of this regulation and lead to the development of potential therapeutic applications [24•].

\section{Antiproliferation actions of Vitamin D and Vitamin D receptor}

Vitamin D and its derivatives are being extensively explored as chemo-preventive and even chemo-therapeutic agents [36] because of Vitamin D's antiproliferative role. One mechanism of $1,25(\mathrm{OH})_{2} \mathrm{D}_{3}$ action is VDR's inhibition of the Wnt/beta-catenin activity $[37,38]$. The study of Kaler et al. [39••] has shown that macrophage-derived IL-1 $\beta$ induces canonical Wnt signaling in colon cancer cells and promotes their growth. Notably, $1,25(\mathrm{OH})_{2} \mathrm{D}_{3}$ is able to interrupt this crosstalk by blocking the constitutive activation of STAT1 and the production of IL-1 $\beta$ in macrophages and therefore - in a VDR-dependent manner - inhibits the ability of macrophages to activate Wnt signaling in colon carcinoma cells. However, a recent study showed that Vitamin D/VDR increases TCF-4 expression, a transcriptional regulator of the $\mathrm{Wn} /$ beta-catenin activity [40]. Recent studies have indicated that TCF-4 functions as a transcriptional repressor that restricts colorectal cancer cell growth. These data suggest that the $1,25(\mathrm{OH})_{2} \mathrm{D}_{3} / \mathrm{VDR}$-mediated increase in TCF- 4 may have a protective role in colon cancer as well as Crohn's disease [40].

Cancer cells often contain abundant mutant p53 (mutp53). Recently, it has been shown that Mutp53 interacts functionally and physically with VDR. Mutp53 is recruited to VDR-regulated 
target genes and modulates their expression. Furthermore, Mutp53 increases the nuclear accumulation of VDR [41••].

\section{Controversy in Vitamin D usage}

Researchers are recommending Vitamin D supplementation at historically unprecedented levels, which may result in the revision of current guidelines (National-Academy-ofSciences, 009) [42,43]. Treatment of Vitamin D insufficiency/deficiency has two phases: restoration of $25 \mathrm{OHD}$ levels to more than $30 \mathrm{ng} / \mathrm{ml}$, and maintenance of serum 25OHD in that range [43].

Considering the broad physiological relevance of Vitamin D, it may potentially become a treatment for human diseases. The biggest obstacle to clinical use of Vitamin D is its potent hypercalcemic effect. Additional research is required to quantify proper dosage.

Researchers have also warned against the usage of Vitamin D in infectious and autoimmune diseases $[10 \bullet, 25]$. Increased levels of Vitamin D in the immune system may contribute to the dysfunction of nuclear receptors and subsequent negative consequences for immune and endocrine function $[10 \bullet, 25]$.

The data on the MutP53 interaction with VDR also indicate that extra caution should be taken in using Vitamin D or its analogs in individualized cancer therapy [41••].

Little is known about the molecular mechanisms responsible for the dysfunction of VDR in human diseases. If we do not understand the mechanism of VDR, the Vitamin D sensor, Vitamin D may not be used effectively and efficiently as a treatment.

Selective usage of Vitamin D supplement or analogs needs to be tailored to the individual level because of the uncertainty of Vitamin D and VDR in the pathogenesis of diseases.

\section{Conclusion}

Manipulating the level of $1,25(\mathrm{OH})_{2} \mathrm{D}_{3}$ in the body and restoring the function of VDR may represent a new approach to treating autoimmune diseases. $1,25(\mathrm{OH})_{2} \mathrm{D}_{3}$ has potent immunomodulatory properties that have promoted its potential use in the prevention and treatment of infectious disease and autoimmune conditions [44•].

There is increasing concern regarding the use of Vitamin D as a cheap and easy supplement for disease prevention. We urgently need to advance our understanding of how VDR is involved in the pathogenesis of human disease and therapeutics to prevent and treat various illnesses.

\section{Acknowledgments}

This work was supported by the National Institutes of Health (DK075386-0251, R03DK089010-01), the American Cancer Society (RSG-09-075-01-MBC), and the New York State's Empire State Stem Cell Board (N09G-279).

\section{References and recommended reading}

Papers of particular interest, published within the annual period of review, have been highlighted as:

- of special interest

•• of outstanding interest 
Additional references related to this topic can also be found in the Current World Literature section in this issue (pp. 000-000).

1. Demay MB. Mechanism of vitamin D receptor action. Ann N Y Acad Sci 2006;68:204-213. [PubMed: 16831920]

2. Wang Y, Becklund BR, DeLuca HF. Identification of a highly specific and versatile vitamin D receptor antibody. Arch Biochem Biophys 2010;494:166-177. [PubMed: 19951695] A very useful paper to identify the specific anti-VDR antibody using immunological methods.

3. Bouillon R, Carmeliet G, Verlinden L, et al. Vitamin D and human health: lessons from vitamin D receptor null mice. Endocr Rev 2008;29:726-776. [PubMed: 18694980]

4. Carlberg C, Seuter S. A genomic perspective on vitamin D signaling. Anticancer Res 2009;29:34853493. [PubMed: 19667142] A review of the Vitamin D/VDR signaling at genetic level.

5. Adams JS, Hewison M. Unexpected actions of vitamin D: new perspectives on the regulation of innate and adaptive immunity. Nat Clin Pract Endocrinol Metab 2008;4:80-90. [PubMed: 18212810]

6. Holmgren J, Czerkinsky C. Mucosal immunity and vaccines. Nat Med 2005;11 (Suppl):S45-S53. [PubMed: 15812489]

7. Ghoreishi M, Bach P, Obst J, et al. Expansion of antigen-specific regulatory T cells with the topical vitamin D analog calcipotriol. J Immunol 2009;182:6071-6078. [PubMed: 19414758]

8. Von Essen MR, Kongsbak M, Schjerling P, et al. Vitamin D controls T cell antigen receptor signaling and activation of human T cells. Nat Immunol 2010;11:344-349. [PubMed: 20208539] This work clearly implicates Vitamin D/VDR signaling in regulation of $\mathrm{T}$ cell antigen receptor signaling and activation of human $\mathrm{T}$ cells.

9. Kamen DL, Tangpricha V. Vitamin D and molecular actions on the immune system: modulation of innate and autoimmunity. J Mol Med 2010;88:441-450. [PubMed: 20119827] A recent review on Vitamin D and immunoregulation.

10. Albert PJ, Proal AD, Marshall TG. Vitamin D: the alternative hypothesis. Autoimmun Rev 2009;8:639-644. [PubMed: 19393200] An article summarizing one view of the controversy surrounding Vitamin D in prevention and therapy of autoimmune diseases.

11. Xue Y, Fleet JC. Intestinal vitamin D receptor is required for normal calcium and bone metabolism in mice. Gastroenterology 2009;136:1317-1327. e1-2. [PubMed: 19254681]

12. Lim WC, Hanauer SB, Li YC. Mechanisms of disease: vitamin D and inflammatory bowel disease. Nat Clin Pract Gastroenterol Hepatol 2005;2:308-315. [PubMed: 16265284]

13. Abreu MT, Kantorovich V, Vasiliauskas EA, et al. Measurement of vitamin D levels in inflammatory bowel disease patients reveals a subset of Crohn's disease patients with elevated 1,25dihydroxyvitamin D and low bone mineral density. Gut 2004;53:1129-1136. [PubMed: 15247180]

14. Wada K, Tanaka H, Maeda K, et al. Vitamin D receptor expression is associated with colon cancer in ulcerative colitis. Oncol Rep 2009;22:1021-1025. [PubMed: 19787215]

15. Yu S, Bruce D, Froicu M, et al. Failure of T cell homing, reduced CD4/CD8alphaalpha intraepithelial lymphocytes, and inflammation in the gut of vitamin D receptor KO mice. Proc Natl Acad Sci USA 2008;105:20834-20839. [PubMed: 19095793]

16. Kong J, Zhang Z, Musch MW, et al. Novel role of the vitamin D receptor in maintaining the integrity of the intestinal mucosal barrier. Am J Physiol Gastrointest Liver Physiol 2008;294:G208-G216. [PubMed: 17962355]

17. Fujita H, Sugimoto K, Inatomi S, et al. Tight junction proteins claudin-2 and 12 are critical for vitamin D-dependent $\mathrm{Ca}^{2+}$ absorption between enterocytes. Mol Biol Cell 2008;19:1912-1921. [PubMed: 18287530]

18. Jeffery LE, Burke F, Mura M, et al. 1,25-Dihydroxyvitamin D3 and IL-2 combine to inhibit T cell production of inflammatory cytokines and promote development of regulatory $\mathrm{T}$ cells expressing CTLA-4 and FoxP3. J Immunol 2009;3:5458-5467. [PubMed: 19843932] An immunologic study demonstrating the importance of Vitamin D and IL-2 in T cell functions.

19. Sun J, Kong J, Duan Y, et al. Increased NF-kappaB activity in fibroblasts lacking the vitamin D receptor. Am J Physiol Endocrinol Metab 2006;291:E315-E322. [PubMed: 16507601]

20. Wu S, Liao PA, Xia Y, et al. Vitamin D receptor negatively regulates bacterial-stimulated NF-kappaB activity in intestine. Am J Pathol. 2010 Jun 21; [Epub ahead of print]. 
21. Wu S, Xia Y, Liu X, Sun J. Vitamin D receptor deletion leads to reduced level of IkappaBalpha protein through protein translation, protein-protein interaction, and posttranslational modification. Int J Biochem Cell Biol. 2009 November 30; [Epub ahead of print].

22. Wang TT, Dabbas B, Laperriere D, et al. Direct and indirect induction by 1,25-dihydroxyvitamin D3 of the NOD2/CARD15-defensin beta2 innate immune pathway defective in Crohn disease. J Biol Chem 2010;285:2227-2231. [PubMed: 19948723] A recent progress links Vitamin D and IBD.

23. Maruotti N, Cantatore FP. Vitamin D and the immune system. J Rheumatol 2010;37:491-495. [PubMed: 20080911]

24. Gombart AF. The vitamin D-antimicrobial peptide pathway and its role in protection against infection. Future Microbiol 2009;4:1151-1165. [PubMed: 19895218] An important article summarizing the functions of Vitamin D in anti-infection.

25. Waterhouse JC, Perez TH, Albert PJ. Reversing bacteria-induced vitamin D receptor dysfunction is key to autoimmune disease. Ann N Y Acad Sci 2009;1173:757-765. [PubMed: 19758226]

26. Yuk JM, Shin DM, Lee HM, et al. Vitamin D3 induces autophagy in human monocytes/macrophages via cathelicidin. Cell Host Microbe 2009;6:231-243. [PubMed: 19748465] This paper provides a mechanistic explanation for the function of Vitamin D3 in autophagy.

27. Fabri M, Modlin RL. A vitamin for autophagy. Cell Host Microbe 2009;6:201-203. [PubMed: 19748462]

28. Montoya D, Cruz D, Teles RM, et al. Divergence of macrophage phagocytic and antimicrobial programs in leprosy. Cell Host Microbe 2009;6:343-353. [PubMed: 19837374] An interesting study dissects the differential regulation of macrophages in phagocytic and antimicrobial functions.

29. Koslowski MJ, Beisner J, Stange EF, Wehkamp J. Innate antimicrobial host defense in small intestinal Crohn's disease. Int J Med Microbiol 2010;300:34-40. [PubMed: 19850516]

30. Wehkamp J, Wang G, Kubler I, et al. The Paneth cell alpha-defensin deficiency of ileal Crohn's disease is linked to Wnt/Tcf-4. J Immunol 2007;179:3109-3118. [PubMed: 17709525]

31. Lagishetty V, Misharin AV, Liu NQ, et al. Vitamin D deficiency in mice impairs colonic antibacterial activity and predisposes to colitis. Endocrinology 2010;151:2423-2432. [PubMed: 20392825] This study explores the intestinal bacteria and Vitamin D status in a colitis animal model.

32. Gudmundsson GH, Bergman P, Andersson J, et al. Battle and balance at mucosal surfaces -the story of Shigella and antimicrobial peptides. Biochem Biophys Res Commun 2010;396:116-119. [PubMed: 20494122]

33. D'Aldebert E, Biyeyeme Mve MJ, Mergey M, et al. Bile salts control the antimicrobial peptide cathelicidin through nuclear receptors in the human biliary epithelium. Gastroenterology 2009;136:1435-1443. [PubMed: 19245866] This study suggests that the critical role of bile salt and Vitamin D in biliary epithelium.

34. Bartley J. Vitamin D, innate immunity and upper respiratory tract infection. J Laryngol Otol 2010;124:465-469. [PubMed: 20067648]

35. Hansdottir S, Monick MM, Lovan N, et al. Vitamin D decreases respiratory syncytial virus induction of NF-kappaB-linked chemokines and cytokines in airway epithelium while maintaining the antiviral state. J Immunol 2010;184:965-974. [PubMed: 20008294] A careful dissection of changes in the NF-kappaB pathway in virus-infected airway epithelial cells.

36. Fedirko V, Bostick RM, Long Q, et al. Effects of supplemental vitamin D and calcium on oxidative DNA damage marker in normal colorectal mucosa: a randomized clinical trial. Cancer Epidemiol Biomarkers Prev 2010;19:280-291. [PubMed: 20056649]

37. Haussler MR, Haussler CA, Whitfield GK, et al. The nuclear vitamin D receptor controls the expression of genes encoding factors which feed the 'Fountain of Youth' to mediate healthful aging. J Steroid Biochem Mol Biol. 2010 March 20; [Epub ahead of print].

38. Artaza JN, Sirad F, Ferrini MG, Norris KC. 1,25(OH $)_{2}$ vitamin D3 inhibits cell proliferation by promoting cell cycle arrest without inducing apoptosis and modifies cell morphology of mesenchymal multipotent cells. J Steroid Biochem Mol Biol 2010;119:73-83. [PubMed: 20064609]

39. Kaler P, Augenlicht L, Klampfer L. Macrophage-derived IL-1 beta stimulates Wnt signaling and growth of colon cancer cells: a crosstalk interrupted by vitamin D3. Oncogene 2009;28:3892-3902. [PubMed: 19701245] This study demonstrates the cross-talks between macrophages and epithelial cells through Wnt and Vitamin D singling pathways. 
40. Beildeck ME, Islam M, Shah S, et al. Control of TCF-4 expression by VDR and vitamin D in the mouse mammary gland and colorectal cancer cell lines. PLoS One 2009;4:e7872. [PubMed: 19924301]

41. Stambolsky P, Tabach Y, Fontemaggi G, et al. Modulation of the vitamin D3 response by cancerassociated mutant p53. Cancer Cell 2010;17:273-285. [PubMed: 20227041] This study is notable for findings on the interaction between mutated p53 and VDR.

42. Bell TD, Demay MB, Burnett-Bowie SA. The biology and pathology of vitamin D control in bone. J Cell Biochem. 2010 April 23; [Epub ahead of print].

43. Adams JS, Hewison M. Update in vitamin D. J Clin Endocrinol Metab 2010;95:471-478. [PubMed: 20133466]

44. Hewison M. Vitamin D and the intracrinology of innate immunity. Mol Cell Endocrinol 2010;321:103-111. [PubMed: 20156523] A very useful introduction to the progress in Vitamin D. 